\title{
Norois
}

Environnement, aménagement, société

$244 \mid 2017$

Sport, immigration, urbanisation littorale, climat sahélien, biodiversité

\section{Vincent HERBERT et Christophe GIBOUT (dir.), Plaisance et urbanité. L'intégration des ports dans les villes contemporaines}

Nicolas Bernard

\section{CpenEdition}

\section{Journals}

Édition électronique

URL : http://journals.openedition.org/norois/6189

DOI : $10.4000 /$ norois. 6189

ISBN : 978-2-7535-7420-5

ISSN : $1760-8546$

\section{Éditeur}

Presses universitaires de Rennes

\section{Édition imprimée}

Date de publication : 30 décembre 2017

Pagination : $97-98$

ISBN : 978-2-7535-7418-2

ISSN : 0029-182X

Référence électronique

Nicolas Bernard, « Vincent Herbert et Christophe Gibout (dir.), Plaisance et urbanité. L'intégration des ports dans les villes contemporaines », Norois [En ligne], 244 | 2017, mis en ligne le 30 décembre 2017, consulté le 11 janvier 2021. URL : http://journals.openedition.org/norois/6189; DOI : https://doi.org/ 10.4000/norois. 6189 
Vincent Herbert et Christophe Gibout (dir.), 2017. Plaisance et urbanité. L'intégration des ports dans les villes contemporaines, Presses universitaires du Septentrion, coll. « Environnement et société », $241 \mathrm{p}$.

L'ouvrage rassemble les contributions de seize auteurs issus de divers domaines disciplinaires (géographie, histoire, sociologie, droit, économie, gestion, architecture, urbanisme ) dans le but annoncé de croiser leurs regards sur la question de l'intégration des équipements portuaires de plaisance dans les espaces urbains, en analysant les enjeux spatiaux, politiques, sociologiques, juridiques et culturels de ces territoires en recomposition. Cette association de chercheurs en sciences sociales, auxquels se joignent des « praticiens » des territoires, est la bienvenue tant elle permet des approches complémentaires de la question traitée. Cette dernière n'est certes pas nouvelle, et de nombreuses publications produites dans les années 1990 et 2000 ont déjà abordé ces thèmes, mais l'ouvrage permet de les réactualiser dans un contexte particulièrement mouvant et d'apporter des éclairages originaux à partir d'études de cas françaises ou étrangères.

L'ambition de l'ouvrage est clairement exprimée : «Comprendre ce qui se joue dans la relation renouvelée des villes à leurs ports de plaisance». Les quatorze contributions se répartissent dans les quatre parties qui structurent l'ouvrage : Regards socio-historiques sur les ports de plaisance et l'urbanité; Enjeux d'aménagements des relations entre ports de plaisance et villes; Paysages et modes de vie pour l'intégration de la plaisance dans la ville; Dynamique socio-économique de la plaisance et relations à la ville.

Comme dans tout ouvrage collectif, l'apport des contributions est d'intérêt inégal; c'est le propre de ce genre d'exercice. Certaines d'entre elles s'écartent sensiblement de la problématique affichée et reprennent des analyses déjà développées depuis 15 ou 20 ans, notamment sur les pratiques plaisancières, les typologies de plaisanciers ou encore la reconversion des ports traditionnels à la plaisance, sans apporter véritablement d'éléments nouveaux... Nous retiendrons bien évidemment celles qui abordent de front la question posée en proposant une analyse spatiale aboutie et une mise en perspective des enjeux d'aménagement liés aux villes portuaires. À cet égard, les exemples

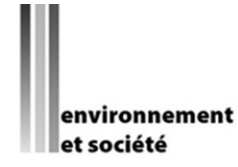

Vincent Herbert Christophe Gibout

(dir.)

\section{Plaisance \& urbanité} L'intégration des ports dans les villes contemporaines

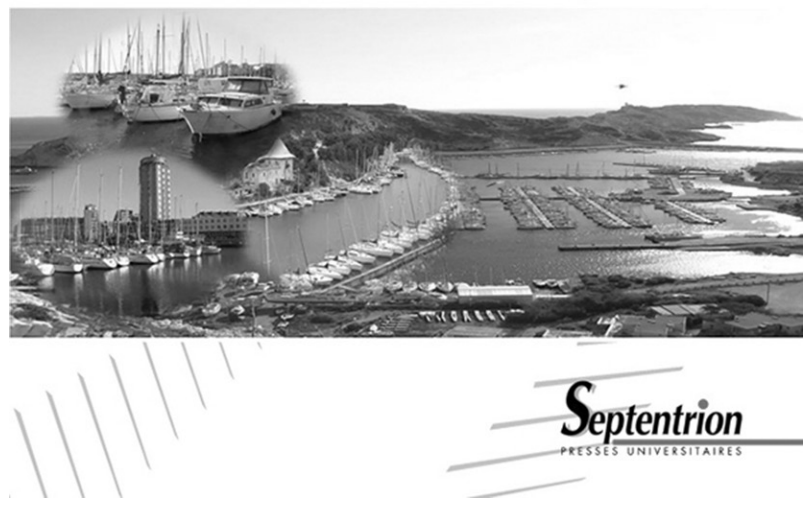

pris à l'étranger et abordés sous l'angle historique (Santa Monica aux États-Unis) ou contemporain (Grande-Bretagne, Belgique, Allemagne, Pays-Bas, Espagne...) apportent un éclairage extrêmement utile dans la mesure où les productions scientifiques nous manquent cruellement sur les situations hors de l'Hexagone. Les exemples pris à Barcelone et à Majorque (P. Ballester) ou à Ijmuiden aux Pays-Bas (H. Kijne, G. De Vries) composent d'excellentes synthèses des enjeux liés aux nouvelles urbanités portuaires. L'intérêt de plusieurs contributions est aussi de montrer que malgré les efforts entrepris par les aménageurs-urbanistes, les professionnels du secteur nautique et les élus, on ne peut que constater la permanence de ruptures entre le port de plaisance et le territoire urbain littoral. 
On peut bien sûr regretter que certains paramètres annonçant la fin d'un cycle pour les ports de plaisance ne soient pas pris en considération, tout particulièrement le vieillissement marqué des usagers des ports de plaisance, qui pose à terme la question du renouvellement de la clientèle portuaire. De même, les conflits d'usage liés aux choix urbanistiques dans les espaces portuaires demanderaient à être davantage explorés, ainsi que les relations particulières «port-port» (entre les ports de plaisance d'une même commune, entre le port de plaisance et les autres infrastructures portuaires ). Des pistes restent donc à ouvrir, comme nous y invitent page $19 \mathrm{~V}$. Herbert et C. Gibout.

Le premier mérite de cet ouvrage est de (re)placer la question des ports de plaisance au cœur des problématiques scientifiques liées aux espaces littoraux et à leur aménagement.

Nicolas BERNARD université de Bretagne occidentale 